\title{
Original
}

\section{Effects of Diluents, Saliva and Other Organics on the Microbicidal Activity of Cetylpyridinium Chloride and Povidone-iodine}

\author{
RIKA URAKAWA ${ }^{1 *}$, JUNYA INUBUSHI ${ }^{1,2}$, HARUKO TOBATA ${ }^{2}$, AND TORU EGUCHI ${ }^{2}$ \\ ${ }^{1} R \& D$, Sunstar Inc., 1-35-10, Kawanishi-cho, Takatsuki, Osaka, 569-1133, Japan \\ ${ }^{2}$ Sunstar Shizuoka Innovation Center, Sunstar Inc., 1002-1, Shimonagakubo, Nagaizumi-cho, Sunto-gun, \\ Shizuoka, 411-0934, Japan
}

Received 17 June, 2019/Accepted 6 November, 2019

\begin{abstract}
Povidone-iodine (PVP-I) is used for infection control and preoperative sterilization of the oral and pharyngeal regions. Marketed preparations containing cetylpyridinium chloride (CPC) are used to inhibit growth of oral bacteria. We conducted an in vitro study of the sterilizing effects of these microbicides on $\mathbf{1 0}$ oral bacterial strains and fungi related to pneumonia and periodontal disease, after dilution with phosphate-buffered saline (PBS), saliva, and components in saliva. The CPC solution was evaluated at $50 \mathrm{mg} / 100 \mathrm{~mL}$, which is the concentration used in products. CPC sterilized all strains within 1 minute. Prolongation of the sterilization time associated with dilution was more gradual in comparison to PVP-I solution. CPC sterilized 7 of 10 microbial strains within 3 minutes at $3 \mathrm{mg} / 100 \mathrm{~mL}$. At $500 \mathrm{mg} / 100 \mathrm{~mL}$, which is near the upper limit of the concentration that is actually used, PVP-I solution sterilized 7 microbial strains within 3 minutes. However, PVP-I had no sterilization effect when diluted to $100 \mathrm{mg} / 100 \mathrm{~mL}$ or lower. With addition of saliva, PVP-I sterilized 2 microbial strains within 3 minutes at $500 \mathrm{mg} / 100 \mathrm{~mL}$, whereas CPC solution sterilized 9 microbial strains within 1 minute at $50 \mathrm{mg} / 100 \mathrm{~mL}$. Our results show that in use influenced by dilution with saliva, CPC is likely to maintain a strong sterilization effect, whereas PVP-I may have a reduced effect.
\end{abstract}

Key words : Cetylpyridinium chloride / Povidone-iodine / Aspiration pneumonia / Sterilization / Mouthwash.

\section{INTRODUCTION}

The incidence of aspiration pneumonia increases with advancing age, and the related factors include dysphagia, microbes in the oral cavity, and malnutrition (DiBardino and Wunderink, 2015). Oral care decreases the risk of aspiration pneumonia, and patients in healthcare facilities who receive oral hygiene for 2 years have significantly lower mortality from pneumonia compared to patients who do not receive this care (Yoneyama et al., 1999). Furthermore, a multicenter, case-control study with propensity score matching analysis showed that perioperative oral care decreased the risk of postoperative pneumonia after esophageal cancer surgery

*Corresponding author. Tel: +81-72-681-0821; Fax: +81-72681-0834, E-mail : rika.urakawa(a)jp.sunstar.com
(Soutome et al., 2017). However, professional oral care requires dentists or dental hygienists. Self-care products are needed to allow patients to decrease oral microbes themselves and reduce the burden on medical staff at health-care facilities.

Povidone-iodine (PVP-I) is a microbicide that is commonly used in hospitals and homes to prevent oral and throat infection. However, gargling with PVP-I has been shown to be slightly less effective for throat infection compared to gargling with water, although with no significant difference (Satomura et al., 2005). A review of the effect of oral care with chlorhexidine $(\mathrm{CHX})$ or PVP-I for prevention of ventilator-associated pneumonia showed that $\mathrm{CHX}$ was effective, whereas the effect of PVP-I was unclear (Labeau et al., 2011). PVP-I is readily inactivated by organics, including blood and saliva (Ogura et al., 1999), and its effect may be decreased 
by dilution with saliva in the oral cavity. However, despite increased discussion of the limitations of PVP-I, it is still used without clear knowledge of its effects.

Mouthwashes containing $0.12 \%$ or $0.2 \% \mathrm{CHX}$ gluconate or hydrochloride are used as microbicides worldwide (Najafi et al., 2012). CHX is microbicidal for some microbes. For S. mutans, an MIC (minimum inhibitory concentration) of $70 \mathrm{mg} / \mathrm{L}(0.007 \%)$ and an $\mathrm{MBC}$ (minimum bactericidal concentration) of $150 \mathrm{mg} / \mathrm{L}$ (0.015\%) have been reported (Uzer Celik et al., 2016). While the microbicidal effects of $\mathrm{CHX}$ on oral microorganisms have been frequently reported, anaphylactic shock at the time of use is a serious problem. In Japan, the $0.12 \%$ and $0.2 \%$ concentrations are not approved due to allergy concerns. The concentration of undiluted $\mathrm{CHX}$-containing mouthwashes is restricted to $0.05 \%$ or less and they are used after dilution (Sugita et al., 2014). Mouthwashes, tooth pastes and oral agents for sore throat containing cetylpyridinium chloride (CPC), which is a cationic surfactant similar to $\mathrm{CHX}$, are also commonly used. Anti-plaque and anti-gingivitis effects of 0.05\% CPC products have been reported (Shim et al., 2012, Sreenivasan et al., 2013, Lee et al., 2017), and they are safely used worldwide. CPC is a long-acting microbicide that is absorbed on tooth surfaces (van der Mei et al., 1990) and is inactivated by organics (Takagi et al., 1989).

It is unclear how saliva and dilution influence the activities of CPC and PVP-I. Therefore, in this study, the microbicidal effects of PVP-I, CPC and commercial products containing these compounds and $\mathrm{CHX}$ were examined on oral microbial strains. Sterilization effects were compared after dilution with phosphate-buffered saline (PBS) and saliva, and after addition of components of saliva.

\section{MATERIALS AND METHODS}

\section{Test preparations}

PVP-I (Sigma-Aldrich, St. Louis, MO), CPC (Merck KGaA, Darmstadt, Germany), and the following commercial products were used in the study: PVP-I gargle containing $7 \%$ PVP-I to be diluted 15 - to 30-fold (approximately $0.23 \%$ to $0.47 \%$ ) at use; CPC mouthwash containing $0.05 \%$ CPC with glycyrrhizic acid dipotassium salt and benzalkonium chloride (CPC mouthwash A); CPC mouthwash containing 0.05\% CPC with tranexamic acid (CPC mouthwash B); and $\mathrm{CHX}$ mouthwash containing $0.05 \% \mathrm{CHX}$ to be diluted to $0.0001 \%$ to $0.0006 \%$ at use.

\section{Microbial strains and culture method}

The following 10 strains were used: pneumonia-related bacteria: Streptococcus pneumoniae ATCC33400
(S.p), Streptococcus intermedius ATCC27335 (S.i), Streptococcus constellatus subsp. constellatus ATCC27823 (S.c), Staphylococcus aureus IF012732 (S.a), Pseudomonas aeruginosa IFO13275 (P.a); periodontopathic bacteria: Porphyromonas gingivalis ATCC33277 (P.g), Fusobacterium nucleatum ATCC25586 (F.n), Filifactor alocis ATCC35896 (F.a); dental caries pathogen: Streptococcus mutans ATCC25175 (S.m); and fungi: Candida albicans NBRC1594 (C.a). Culture conditions for microbes are shown in Table 1. The microbial strains were cultured on appropriate agar media and fluid media $(10 \mathrm{~mL})$.

\section{Microbicidal tests of microbicides and commercial products}

Microbicidal tests with inactivated solution containing 10\% Tween 80 , 3\% lecithin from soybean, and 0.5\% sodium thiosulfate were performed to compare the microbicidal activities of PVP-I and CPC based on the time required for sterilization (Kunisada et al., 1999). Precultured microbes were suspended in appropriate media (10 mL) and adjusted to the McFarland No. 0.5 standard to prepare a microbial suspension. PVP-I or CPC were dissolved in distilled sterile water and diluted to eleven concentrations: $0.5,1,3,5,10,30,50,100$, 300, 500 and $1000 \mathrm{mg} / 100 \mathrm{~mL}$. Commercial products were prepared as 2-, 3.75-, 7.5-, 15-, 30-, 60-, 120-, 240- and 480-fold diluted stock solutions.

Saliva, 1\% (w/v) albumin, rabbit serum or PBS (100 $\mu \mathrm{L}$ ) was added to diluted PVP-I, CPC or commercial products $(100 \mu \mathrm{L}) .1 \%(\mathrm{w} / \mathrm{v})$ albumin or rabbit serum was added to some test microbes (S.m, S.a, P.a, S.p, C.a). Each microbial suspension $(20 \mu \mathrm{L})$ was added to the test solution and immediately mixed at room temperature. The mixture $(20 \mu \mathrm{L})$ was collected 0.25 , $0.5,1,3,5,10$ and 30 min after mixing and inoculated into inactivated solution $(180 \mu \mathrm{L})$. The resulting solution $(20 \mu \mathrm{L})$ was inoculated into appropriate medium with $1 \%$ Tween $80,0.3 \%$ lecithin, $0.05 \%$ sodium thiosulfate $(180 \mu \mathrm{l})$. After incubation for 72 hours under appropriate conditions for each microbe, growth was checked visually based on the turbidity of the broth. Additionally, $F$. alocis was inoculated on agar medium and viability was assessed by colony formation.

Saliva samples $(40 \mathrm{~mL})$ were collected from 3 healthy volunteers at rest from 9 to $11 \mathrm{am}$, mixed three times using a 23-G syringe, and centrifuged (10000 $\mathrm{rpm}, 4^{\circ} \mathrm{C}, 5 \mathrm{~min}$ ). The supernatant (saliva) was sterilized with ultraviolet light for $1 \mathrm{~h}$. Saliva samples were collected with attention to three ethical considerations: 1) collection was non-invasive, 2) was performed in healthy volunteers at Sunstar Inc., with their prior consent, and 3) saliva samples were mixed after being collected so that they could not be identified. Albumin 
TABLE 1. Culture conditions for test microbes

\begin{tabular}{|c|c|c|c|c|c|c|}
\hline \multirow{3}{*}{ microbe } & \multirow{3}{*}{ Strain } & \multirow{3}{*}{$\begin{array}{l}\text { Passage culture } \\
\text { Agar medium }\end{array}$} & \multicolumn{4}{|c|}{ Fluid culture } \\
\hline & & & \multirow{2}{*}{ Medium } & \multirow{2}{*}{ Culture condition } & \multicolumn{2}{|c|}{ Time (hour) } \\
\hline & & & & & Preculture & Culture after test \\
\hline P. gingivalis & ATCC33277 & \multirow{7}{*}{ Blood agar } & $\mathrm{TSB}+\mathrm{Y} / \mathrm{H}$ & \multirow{4}{*}{ Anaerobic } & 48 & \multirow{10}{*}{72} \\
\hline F. nucleatum & ATCC25586 & & GAM & & 18 & \\
\hline F. alocis & ATCC35896 & & ATCC1490 & & 72 & \\
\hline S. mutans & ATCC25175 & & \multirow{2}{*}{$\mathrm{BHI}$} & & \multirow{2}{*}{18} & \\
\hline S. pneumoniae & ATCC33400 & & & Aerobic & & \\
\hline S. intermedius & ATCC27335 & & \multirow{2}{*}{$\mathrm{TSB}+\mathrm{Y} / \mathrm{H}$} & \multirow{2}{*}{ Anaerobic } & \multirow{2}{*}{24} & \\
\hline S. constellatus & ATCC27823 & & & & & \\
\hline S. aureus & IFO12732 & \multirow{2}{*}{$\mathrm{BHI}$} & \multirow{2}{*}{$\mathrm{BHI}$} & \multirow{3}{*}{ Aerobic } & \multirow{3}{*}{18} & \\
\hline P. aeruginosa & IF013275 & & & & & \\
\hline C. albicans & NBRC1594 & Candida GS & Sabouraud & & & \\
\hline
\end{tabular}

$\mathrm{BH}$ refers to Brain Heart Infusion, which is supplied as agar or broth. TSB+Y/H medium was supplemented with yeast extract (1 $\mathrm{mg} / \mathrm{mL})$, hemin $(5 \mu \mathrm{g} / \mathrm{mL})$, and vitamin $\mathrm{K} 1(0.5 \mu \mathrm{g} / \mathrm{mL})$. GAM refers to Gifu Anaerobic Medium and was used as broth.

(Sigma-Aldrich, St. Louis, MO) was dissolved in distilled sterile water to prepare a $1 \%(\mathrm{w} / \mathrm{v})$ solution. Stock solutions of rabbit serum (Biowest, Nuaillé, France) were used in the study.

\section{RESULTS}

\section{Sterilization times of CPC and PVP-I with test microbial strains}

After adding PBS as a control, CPC and PVP-I solutions sterilized all microbial strains, including pneumonia-related bacteria, within 3 min at a concentration of $1000 \mathrm{mg} / 100 \mathrm{~mL}$. Sterilization time increased with decreased concentrations of both agents. For diluted CPC, this increase was not rapid: 9 of 10 strains were sterilized within $30 \mathrm{~s}$ and all strains within $1 \mathrm{~min}$ at $30 \mathrm{mg} / 100 \mathrm{~mL}$; and 7 of 10 strains within $3 \mathrm{~min}$ at 3 $\mathrm{mg} / 100 \mathrm{~mL}$. In contrast, PVP-I sterilized 7 of 10 strains within $3 \mathrm{~min}$ at $500 \mathrm{mg} / 100 \mathrm{~mL}$, but the sterilizing effect decreased significantly at $<100 \mathrm{mg} / 100 \mathrm{~mL}$ (Table 2-I).

\section{Effects of added materials on sterilization times of CPC and PVP-I}

Sterilization times of CPC and PVP-I solutions with added saliva were higher than those with added PBS. After addition of saliva, PVP-I sterilized 2 of 10 microbial strains at $500 \mathrm{mg} / 100 \mathrm{~mL}$, whereas CPC sterilized 9 of 10 strains within $3 \mathrm{~min}$ at $30 \mathrm{mg} / 100 \mathrm{~mL}$ and did not show a rapid increase in sterilization time with dilution, compared with PVP-I (Table 2-II). After addition of 1\% albumin, the CPC and PVP-I solutions sterilized all of 5 strains at $1000 \mathrm{mg} / 100 \mathrm{~mL}$; however, CPC had a sterilizing effect at a lower concentrations than PVP-I (Table 2-III). After addition of rabbit serum, CPC sterilized 2 of 5 strains at $500-1000 \mathrm{mg} / 100 \mathrm{~mL}$, whereas PVP-I had no sterilizing effect on 5 strains (Table 2-IV).

\section{Comparison of sterilization times of commercial products with test microbial strains}

PVP-I gargle sterilized 7 of 10 microbial strains within $30 \mathrm{~s}$ at $467 \mathrm{mg} / 100 \mathrm{~mL}$ (15-fold dilution), the upper limit concentration for oral use. Sterilization effects decreased at $233 \mathrm{mg} / 100 \mathrm{~mL}$ (30-fold dilution), the lower limit concentration, at which PVP-I gargle had no effect on 8 of 10 strains. CPC mouthwashes A and B showed a slow increase in sterilization times at diluted concentrations (Table 3-I). CHX mouthwash sterilized all strains within $5 \mathrm{~min}$ at $50 \mathrm{mg} / 100 \mathrm{~mL}$ (stock solution), but had no sterilizing effect on all strains at 0.42 to $0.83 \mathrm{mg} / 100 \mathrm{~mL}$ (120 to 60 -fold dilution), which is close to the upper limit for oral use.

\section{Effects on sterilization time of addition of saliva to commercial products}

Saliva added to all commercial products prolonged the sterilization time (Table 3-II). All products were tested against the 10 microbial strains at concentrations for oral use. CPC mouthwashes A and B had sterilizing effects on 9 strains, PVP-I gargle sterilized 3 strains, and $\mathrm{CHX}$ mouthwash had no effect on any strains. At 2-fold dilution of the concentration for oral use, CPC mouthwashes A and B sterilized 8 strains within 5 min. PVP-I gargle sterilized 2 strains within 5 min, and $\mathrm{CHX}$ mouthwash had no sterilizing effect on any strains. 
TABLE 2. Sterilization times of microbicides with test microbe strains

I. Control

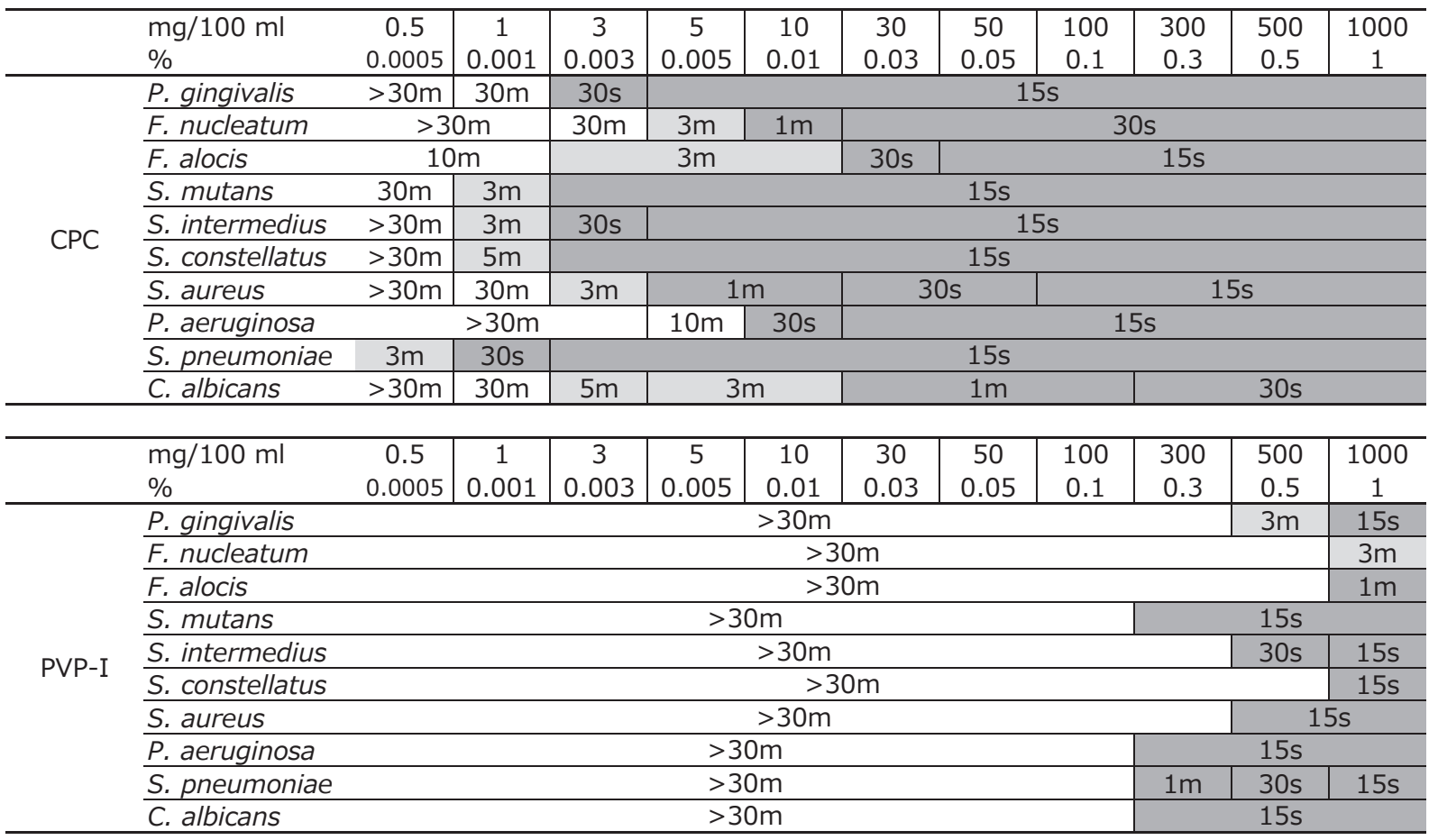

II. Saliva added

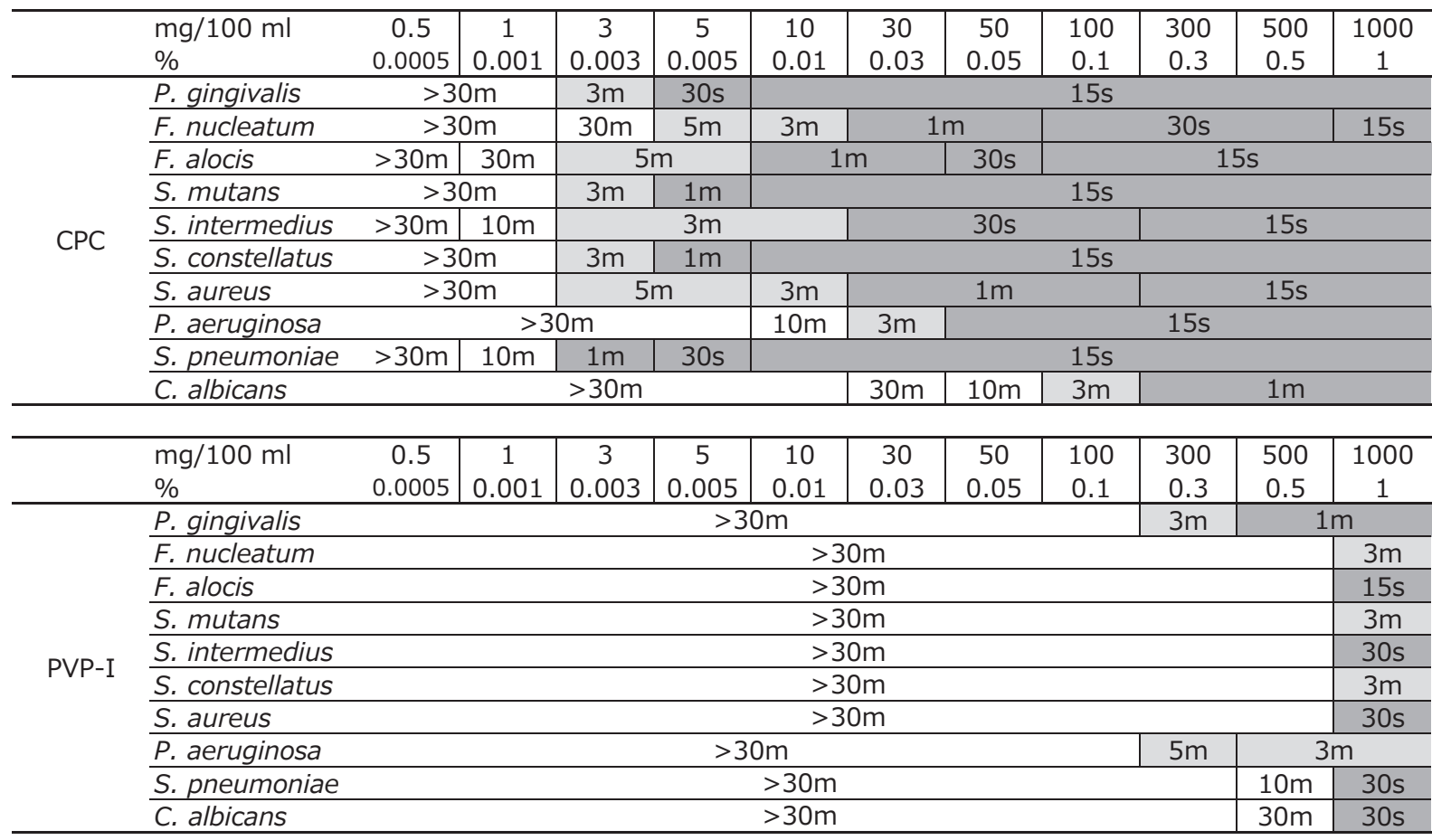


III. $1 \%$ albumin added

\begin{tabular}{|c|c|c|c|c|c|c|c|c|c|c|c|c|}
\hline & $\begin{array}{l}\mathrm{mg} / 100 \mathrm{ml} \\
\%\end{array}$ & $\begin{array}{c}0.5 \\
0.0005 \\
\end{array}$ & $\begin{array}{c}1 \\
0.001 \\
\end{array}$ & $\begin{array}{c}3 \\
0.003 \\
\end{array}$ & $\begin{array}{c}5 \\
0.005 \\
\end{array}$ & $\begin{array}{c}10 \\
0.01 \\
\end{array}$ & $\begin{array}{c}30 \\
0.03 \\
\end{array}$ & $\begin{array}{c}50 \\
0.05 \\
\end{array}$ & $\begin{array}{l}100 \\
0.1 \\
\end{array}$ & $\begin{array}{l}300 \\
0.3 \\
\end{array}$ & $\begin{array}{l}500 \\
0.5 \\
\end{array}$ & $\begin{array}{c}1000 \\
1 \\
\end{array}$ \\
\hline \multirow{7}{*}{ CPC } & S. mutans & \multicolumn{4}{|c|}{$>30 \mathrm{~m}$} & $3 m$ & \multicolumn{6}{|c|}{$15 s$} \\
\hline & S. aureus & \multicolumn{6}{|c|}{$>30 m$} & $3 \mathrm{~m}$ & \multicolumn{3}{|c|}{$1 \mathrm{~m}$} & $15 s$ \\
\hline & $P$. aeruginosa & \multicolumn{6}{|c|}{$>30 m$} & $30 \mathrm{~m}$ & $10 \mathrm{~m}$ & $1 \mathrm{~m}$ & \multicolumn{2}{|c|}{$15 \mathrm{~s}$} \\
\hline & S. pneumoniae & \multirow{2}{*}{\multicolumn{5}{|c|}{$\begin{array}{r}>30 m \\
>30 m\end{array}$}} & & $30 \mathrm{~m}$ & $10 \mathrm{~m}$ & $1 \mathrm{~m}$ & \multicolumn{2}{|c|}{$15 \mathrm{~s}$} \\
\hline & C. albicans & & & & & & \multicolumn{4}{|c|}{$30 \mathrm{~m}$} & $5 \mathrm{~m}$ & $3 m$ \\
\hline & $\mathrm{mg} / 100 \mathrm{ml}$ & 0.5 & 1 & 3 & 5 & 10 & 30 & 50 & 100 & 300 & 500 & 1000 \\
\hline & $\%$ & 0.0005 & 0.001 & 0.003 & 0.005 & 0.01 & 0.03 & 0.05 & 0.1 & 0.3 & 0.5 & 1 \\
\hline \multirow{5}{*}{ PVP-I } & S. mutans & \multicolumn{10}{|c|}{$>30 m$} & $30 s$ \\
\hline & S. aureus & \multicolumn{10}{|c|}{$>30 \mathrm{~m}$} & $30 s$ \\
\hline & $P$. aeruginosa & \multicolumn{10}{|c|}{$>30 m$} & $15 s$ \\
\hline & S. pneumoniae & \multicolumn{10}{|c|}{$>30 m$} & $15 s$ \\
\hline & C. albicans & \multicolumn{10}{|c|}{$>30 \mathrm{~m}$} & $15 s$ \\
\hline
\end{tabular}

IV. Rabbit serum added

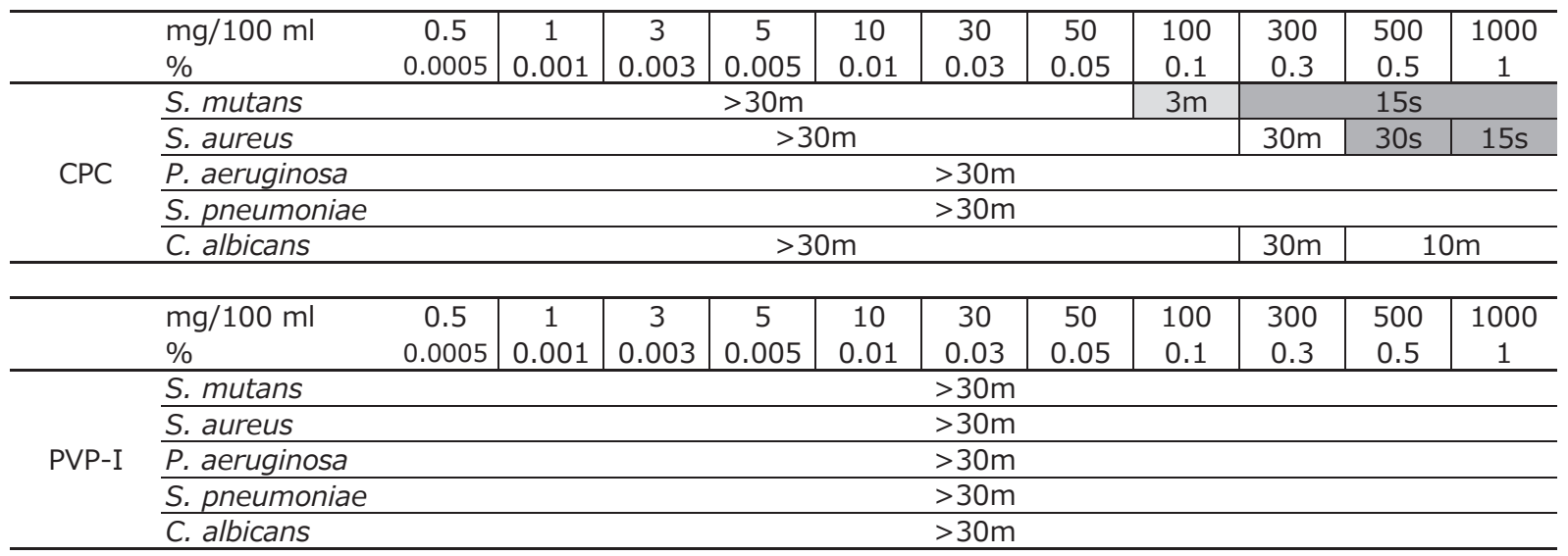

The shortest sterilization time for each microbicide is shown. s: second; m: minute

\section{DISCUSSION}

In this study, microbicidal effects were compared for CPC and PVP-I solutions diluted with PBS or saliva against oral microbial strains, including pneumonia-related bacteria and fungi. The shorter the time taken for sterilization, the higher the sterilizing effect of each product. After PBS was added, CPC sterilized all strains within $1 \mathrm{~min}$ at $50 \mathrm{mg} / 100 \mathrm{~mL}$, which is the concentration actually used. CPC sterilized all strains within $1 \mathrm{~min}$ at $30 \mathrm{mg} / 100 \mathrm{~mL}$ and the sterilization time did not increase rapidly with dilution. PVP-I sterilized 4 to 7 strains within $3 \mathrm{~min}$ at concentrations of 300 to 500 $\mathrm{mg} / 100 \mathrm{~mL}$. These concentrations are close to the 15-fold dilution (467 mg/100 mL), which is the upper limit of the concentration actually used. However, PVP-I had no effect at $100 \mathrm{mg} / 100 \mathrm{~mL}$ or lower, which is lower than the lower limit (30-fold dilution, $233 \mathrm{mg} / 100 \mathrm{~mL}$ ) of the concentration actually used. In a study of several microbial strains using similar procedures (Katsukawa and Tamaru, 1996), S. aureus and S. pneumoniae were sterilized by CPC within 3 min at 5 and $1 \mathrm{mg} / 100 \mathrm{~mL}$, respectively, and by PVP-I within $15 \mathrm{~s}$ and 3 min at 450 $\mathrm{mg} / 100 \mathrm{~mL}$. Our findings are consistent with the results of this previous study.

The sterilizing effect of PVP-I rapidly decreased after saliva was added, whereas that of CPC decreased less. After addition of saliva, PVP-I sterilized only 2 of 10 microbial strains at $500 \mathrm{mg} / 100 \mathrm{~mL}$, whereas CPC sterilized 9 of 10 strains at $50 \mathrm{mg} / 100 \mathrm{~mL}$ (Table 2-II). To examine the effect of blood on microbicides, we added rabbit serum to the CPC and PVP-I solutions. This markedly decreased the sterilizing effects of both, but CPC still sterilized more microbial strains than PVP-I. In particular, CPC had stronger sterilizing effects on $S$. mutans and S. aureus compared to PVP-I; however, 
TABLE 3. Sterilization times of commercial products with test microbe strains

I. Control

\begin{tabular}{|c|c|c|c|c|c|c|c|c|c|c|c|}
\hline \multicolumn{2}{|c|}{ Dilution ratio (fold) } & 480 & 240 & 120 & 60 & 30 & 15 & 7.5 & 3.75 & 2 & 1 \\
\hline & $\mathrm{mg} / 100 \mathrm{ml}$ & 0.10 & 0.21 & 0.42 & 0.83 & 1.67 & 3.33 & 6.67 & 13.33 & 25 & $\underline{50}$ \\
\hline & $\%$ & 0.0001 & 0.0002 & 0.0004 & 0.0008 & 0.0016 & 0.003 & 0.006 & 0.013 & 0.025 & $\underline{0.05}$ \\
\hline & P. gingivalis & & $>30 \mathrm{~m}$ & & $10 \mathrm{~m}$ & & $\mathrm{~m}$ & $30 \mathrm{~s}$ & & $15 \mathrm{~s}$ & \\
\hline & F. nucleatum & & & $0 \mathrm{~m}$ & & $30 \mathrm{~m}$ & 3 & $\mathrm{~m}$ & $1 \mathrm{~m}$ & & Ds \\
\hline & F. alocis & & & 5 & $\mathrm{~m}$ & & & $3 m$ & $1 \mathrm{~m}$ & $30 \mathrm{~s}$ & $15 \mathrm{~s}$ \\
\hline & S. mutans & & $>30 \mathrm{~m}$ & & $10 \mathrm{~m}$ & $5 m$ & & & $15 \mathrm{~s}$ & & \\
\hline CPC mouthwash & S. intermedius & $>3$ & $30 \mathrm{~m}$ & $30 \mathrm{~m}$ & $10 \mathrm{~m}$ & & Os & & 15 & $5 s$ & \\
\hline A & S. constellatus & $>3$ & $30 \mathrm{~m}$ & $10 \mathrm{~m}$ & $1 \mathrm{~m}$ & & Os & & 15 & $5 s$ & \\
\hline & S. aureus & & $>30 \mathrm{~m}$ & & $30 \mathrm{~m}$ & $10 \mathrm{~m}$ & & & $5 m$ & & \\
\hline & P. aeruginosa & & & & $0 \mathrm{~m}$ & & & & $30 \mathrm{~m}$ & & $10 \mathrm{~m}$ \\
\hline & S. pneumoniae & $>3$ & $30 \mathrm{~m}$ & $3 m$ & $30 \mathrm{~s}$ & & & 15 & $5 s$ & & \\
\hline & C. albicans & & & & & $>30 \mathrm{~m}$ & & & & & $30 \mathrm{~m}$ \\
\hline Dilution ratio (fold & & 480 & 240 & 120 & 60 & 30 & 15 & 7.5 & 3.75 & 2 & 1 \\
\hline & $\mathrm{mg} / 100 \mathrm{ml}$ & 0.10 & 0.21 & 0.42 & 0.83 & 1.67 & 3.33 & 6.67 & 13.33 & 25 & 50 \\
\hline & $\%$ & 0.0001 & 0.0002 & 0.0004 & 0.0008 & 0.0016 & 0.003 & 0.006 & 0.013 & 0.025 & 0.05 \\
\hline & P. gingivalis & & $>30 \mathrm{~m}$ & & $30 \mathrm{~m}$ & & $\mathrm{~m}$ & 30 & $0 \mathrm{~s}$ & & $5 s$ \\
\hline & F. nucleatum & & & $>30 \mathrm{~m}$ & & & $10 \mathrm{~m}$ & 31 & $\mathrm{~m}$ & & $\mathrm{~m}$ \\
\hline & F. alocis & $>3$ & $0 \mathrm{~m}$ & 30 & $\mathrm{~m}$ & $10 \mathrm{~m}$ & $5 \mathrm{~m}$ & 31 & $\mathrm{~m}$ & $30 \mathrm{~s}$ & $15 \mathrm{~s}$ \\
\hline & S. mutans & & $>30 \mathrm{~m}$ & & $30 \mathrm{~m}$ & $5 m$ & & & $15 s$ & & \\
\hline CPC mouthwash & S. intermedius & & $>30 \mathrm{~m}$ & & $5 \mathrm{~m}$ & $3 m$ & $1 \mathrm{~m}$ & & $30 \mathrm{~s}$ & & $15 \mathrm{~s}$ \\
\hline$B$ & S. constellatus & & $>30 \mathrm{~m}$ & & $5 \mathrm{~m}$ & & $\mathrm{~m}$ & $30 \mathrm{~s}$ & & $15 \mathrm{~s}$ & \\
\hline & S. aureus & & & $>30 \mathrm{~m}$ & & & $5 \mathrm{~m}$ & & 31 & $\mathrm{~m}$ & \\
\hline & $P$. aeruginosa & & & & $0 \mathrm{~m}$ & & & & 30 & $\mathrm{~mm}$ & \\
\hline & S. pneumoni & & $>30 \mathrm{~m}$ & & $3 m$ & $1 \mathrm{~m}$ & $30 \mathrm{~s}$ & & 15 & & \\
\hline & C. albicans & & & & & $>30 \mathrm{~m}$ & & & & & $30 \mathrm{~m}$ \\
\hline Dilution ratio (fold & & 480 & 240 & 120 & 60 & 30 & 15 & 7.5 & 3.75 & 2 & 1 \\
\hline & $\mathrm{mg} / 100 \mathrm{ml}$ & 14.58 & 29.17 & 58.33 & 117 & 233 & $4 \overline{67}$ & 933 & 1867 & 3500 & 7000 \\
\hline & & 0.01 & 0.03 & 0.05 & 0.11 & $\overline{0.22}$ & $\overline{0.44}$ & 0.875 & 1.75 & 3.5 & 7 \\
\hline & P. gingivalis & & & $>30 \mathrm{~m}$ & & & & & $15 \mathrm{~s}$ & & \\
\hline & F. nucleatum & & & $>3$ & $0 \mathrm{~m}$ & & & & 15 & $5 s$ & \\
\hline & F. alocis & & & & $0 \mathrm{~m}$ & & & & 15 & $5 s$ & \\
\hline & S. mutans & & & $>30 \mathrm{~m}$ & & & & & $15 \mathrm{~s}$ & & \\
\hline P/P_I a aral & S. intermedius & & & $>30 \mathrm{~m}$ & & & $30 \mathrm{~s}$ & & 15 & $5 s$ & \\
\hline PVP-1 gargle & S. constellatus & & & $>30 \mathrm{~m}$ & & & & & $15 \mathrm{~s}$ & & \\
\hline & S. aureus & & & $0 \mathrm{~m}$ & & $30 \mathrm{~s}$ & & & $15 \mathrm{~s}$ & & \\
\hline & P. aerugino & & & $>30 \mathrm{~m}$ & & & & & $15 s$ & & \\
\hline & S. pneumon & & $>30 \mathrm{~m}$ & & & & & $15 \mathrm{~s}$ & & & \\
\hline & C. albicans & & & $>30 \mathrm{~m}$ & & & $10 \mathrm{~m}$ & & 15 & $5 s$ & \\
\hline Dilution ratio (fold & & 480 & 240 & 120 & 60 & 30 & 15 & 7.5 & 3.75 & 2 & 1 \\
\hline & $\mathrm{mg} / 100 \mathrm{ml}$ & 0.10 & 0.21 & 0.42 & 0.83 & 1.67 & 3.33 & 6.67 & 13.33 & 25 & 50 \\
\hline & & 0.0001 & 0.0002 & 0.0004 & 0.0008 & 0.0016 & 0.003 & 0.006 & 0.013 & 0.025 & 0.05 \\
\hline & P. gingivalis & & & $>3$ & $0 \mathrm{~m}$ & & & $3 m$ & $1 \mathrm{~m}$ & & $5 \mathrm{~s}$ \\
\hline & F. nucleatum & & & $>3$ & $0 \mathrm{~m}$ & & & $30 \mathrm{~m}$ & & $30 \mathrm{~s}$ & \\
\hline & F. alocis & & & $>30 \mathrm{~m}$ & & & $30 \mathrm{~m}$ & $5 \mathrm{~m}$ & & $15 \mathrm{~s}$ & \\
\hline & S. mutans & & & & $>30 \mathrm{~m}$ & & & & $3 m$ & $1 \mathrm{~m}$ & $15 \mathrm{~s}$ \\
\hline & S. intermed & & & & $>30 \mathrm{~m}$ & & & & $5 \mathrm{~m}$ & $30 \mathrm{~s}$ & $15 \mathrm{~s}$ \\
\hline mouthwash & S. constellatus & & & & $>30 \mathrm{~m}$ & & & & $3 \mathrm{~m}$ & & $5 s$ \\
\hline & S. aureus & & & & $>30 \mathrm{~m}$ & & & & $10 \mathrm{~m}$ & $3 \mathrm{~m}$ & $30 \mathrm{~s}$ \\
\hline & P. aeruginos & & & $>30 \mathrm{~m}$ & & & $5 \mathrm{~m}$ & $30 \mathrm{~s}$ & & $15 \mathrm{~s}$ & \\
\hline & S. pneumoniae & & & $>3$ & $0 \mathrm{~m}$ & & & $30 \mathrm{~m}$ & $1 \mathrm{~m}$ & & $5 s$ \\
\hline & C. albicans & & & & & $>30 m$ & & & & & $5 \mathrm{~m}$ \\
\hline
\end{tabular}


II. Saliva added

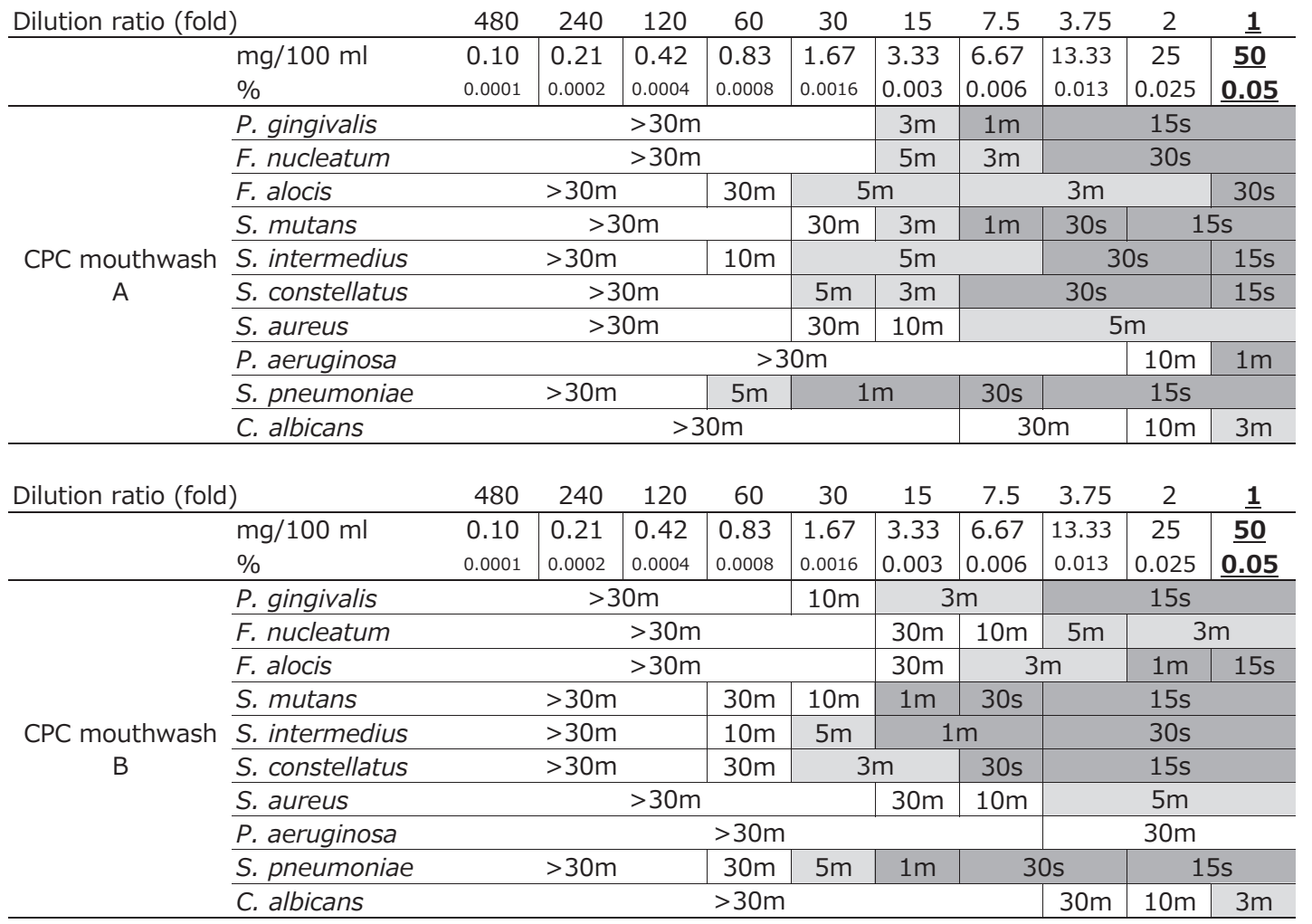

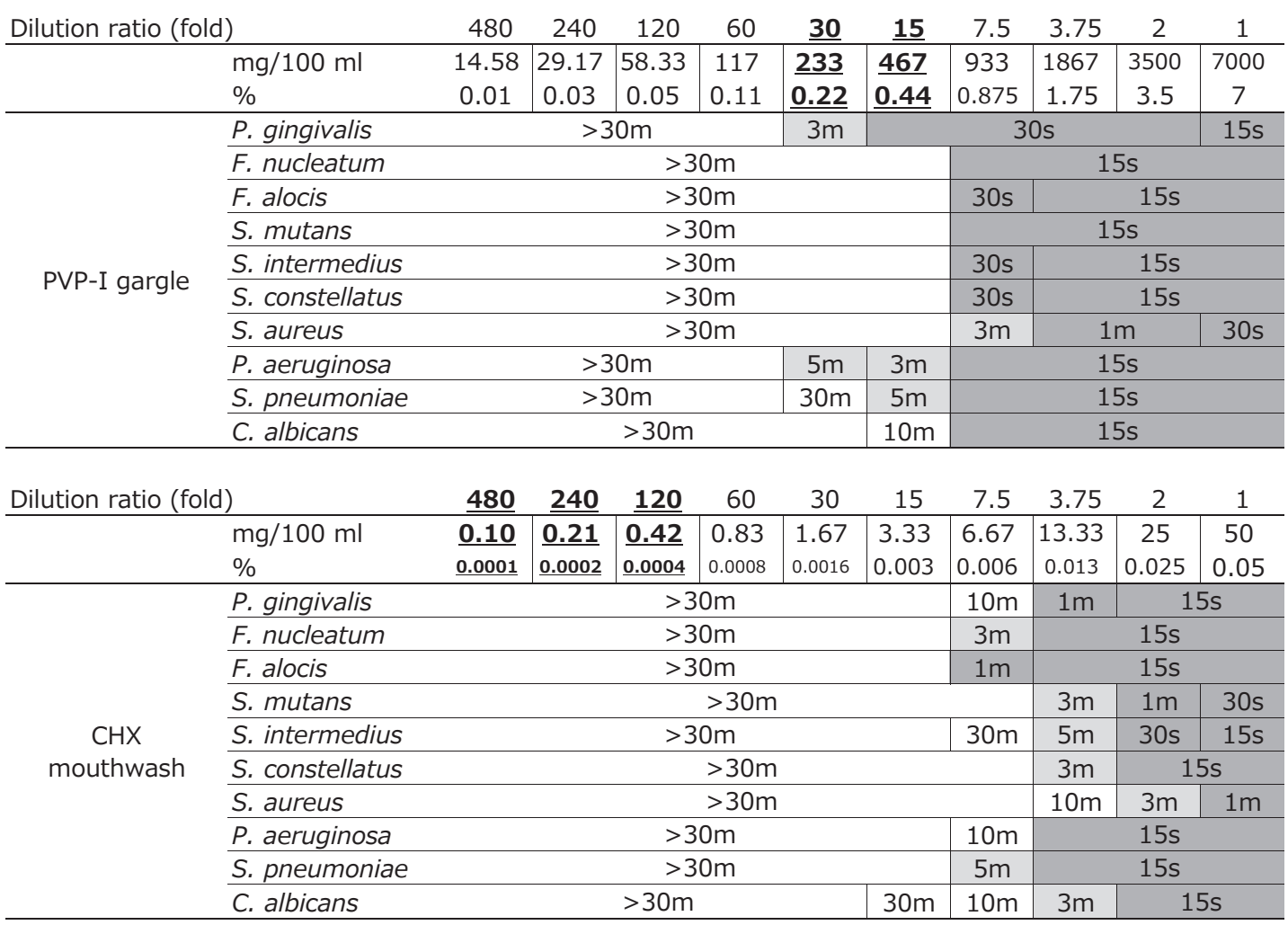

The shortest sterilization time for each product is shown. The \% indicates the concentration relative to the oral dose of the commercial product. s: second; m: minute 
both CPC and PVP-I were less effective for other microbial strains. In this study, undiluted rabbit serum was added to evaluate the microbicidal effects of each microbicide when each was affected most strongly by serum. Sterilizing effects are likely to decrease in a poor periodontal environment with bleeding, and professional oral cleaning is required for patients with poor periodontal conditions. It is assumed that the oral cavity contains a mixture of saliva and blood, both in patients with periodontal diseases and in those with cancer of the mouth who are treated using radiotherapy. While the amount of saliva secreted and amount of bleeding derived from wounds and gingival inflammation in the oral cavity differ among individuals, the sterilizing effect of CPC is likely to be higher than that of PVP-I when the proportion of saliva increases, since the inhibitory effect of saliva was low on CPC, while PVP-I showed no sterilizing effect at $500 \mathrm{mg} / 100 \mathrm{~mL}$ when saliva was added. The effect of albumin, which is present in saliva and blood, on microbicides was also examined. Albumin is present at 4.2 to $5.1 \%$ in blood (Kanai et al., 2010), and 0.14 to $0.64 \%$ as the total protein in saliva (Shibuya et al., 1988). The efficacy of $1 \%$ albumin on various microbicides was investigated to include the total protein content $(0.64 \%)$ in saliva. Addition of albumin increased the concentrations of CPC and PVP-I required to sterilize microbes. CPC sterilized 2 of 5 microbial strains at $50 \mathrm{mg} / 100 \mathrm{~mL}$, whereas PVP-I had no microbicidal effect at $500 \mathrm{mg} / 100$ $\mathrm{mL}$.

The sterilizing effect of PVP-I occurs because free iodine has a strong oxidizing action; thus, a higher concentration of free iodine has a stronger sterilizing effect (Berkelman et al., 1982). Organic material may reduce free iodine, which decreases the oxidizing action and results in decreased reduction of microbes. In contrast, CPC is a microbicide with a cationic hydrophilic group that damages the surfaces of microbes, leading to sterilization (Ogura et al., 1999). The sterilizing effect may be decreased by formation of an ionic interaction between the positively charged CPC and organics; however, the results of this study suggest that organics including saliva and albumin had less effect on CPC than on PVP-I at concentrations for oral use. Clinical studies have shown unclear effects of PVP-I (Satomura et al., 2005, Labeau et al., 2011), and this may be because PVP-I at its oral dose does not have a sufficient sterilizing effect due to the effects of organics such as saliva in the oral cavity.

Similar tendencies to those for CPC and PVP-I were found for commercial products containing these compounds, with CPC products having stronger sterilizing effects than those containing PVP-I. In tests of other products, $\mathrm{CHX}$ mouthwash at the oral dose sterilized fewer microbial strains (Table3-I). Mouthwashes containing $0.12 \%$ or $0.2 \% \mathrm{CHX}$ gluconate or hydrochloride are used as microbicides worldwide. The results of this study suggest pronounced sterilizing effects of $\mathrm{CHX}$-containing products marketed overseas. All 10 microbial strains were sterilized within 5 minutes at a $\mathrm{CHX}$ concentration of $0.05 \%$, which is the concentration in undiluted solution. A mouthwash product containing $\mathrm{CHX}$ used widely in dental clinics in Japan are diluted to $0.0001 \%$ to $0.0006 \%$ due to the concern of an allergic reaction to $\mathrm{CHX}$. This dilution decreased the sterilizing effect in the conditions used in this study. The microbicidal effect of $\mathrm{CHX}$ was affected markedly by the working concentration, and $\mathrm{CHX}$ did not show a microbicidal effect when applied at low concentrations.

In conclusion, dilution or addition of saliva to PVP-I is likely to decrease the sterilization effect of an oral dose, whereas CPC and products containing CPC were influenced less by dilution and saliva, indicating that an oral dose of CPC has a sufficient sterilization effect. Commercial products containing CPC was influenced less by dilution and saliva compared to other products. The concentration CPC that is safely used in Japan has a sufficient sterilization effect even if saliva is present. We plan to conduct clinical studies to reveal the efficacies of CPC products.

\section{REFERENCES}

Berkelman, R.L., Holland, B.W., and Anderson, R.L. (1982) Increased bactericidal activity of dilute preparations of povidone-iodine solutions. J. Clin. Microbiol., 15, 635-639.

DiBardino, D.M., and Wunderink, R.G. (2015) Aspiration pneumonia: a review of modern trends. J. Crit. Care., 30, 40-48.

Kanai, M., Okumura, N., Tozuka, M., and Yatomi, Y. (2010) Clinical Laboratory Mediccine, Thirty-Third Edition (in Japanese). pp.406, Kanehara shuppan, Tokyo.

Katsukawa, C., and Tamaru, A. (1996) A study of the antimicrobial effects of cetylpyridinium chloride (in Japanese). Clinical Report, 30, 401-411.

Kunisada, T., Yamada, K., Oda, S., and Hara, O. (1999) Study of a neutralizer system for in vitro evaluation of antiseptics (in Japanese). Japanese Journal of Environmental Infections, 14, 127-131.

Labeau, S.O., Van de Vyver, K., Brusselaers, N., Vogelaers, D., and Blot, S.I. (2011) Prevention of ventilator-associated pneumonia with oral antiseptics: a systematic review and meta-analysis. Lancet Infect. Dis., 11, 845-854.

Lee, J.E., Lee, J.M., Lee, Y., Park, J.W., Suh, J.Y., Um, H.S., Kim, Y.G. (2017) The antiplaque and bleeding control effects of a cetylpyridinium chloride and tranexamic acid mouth rinse in patients with gingivitis. $J$ Periodontal Implant Sci. 47, 134-142.

Najafi, M.H., Taheri, M., Mokhtari, M.R., Forouzanfar, A., Farazi, F., Mirzaee, M., Ebrahiminik, Z., and Mehrara, R. (2012) Comparative study of $0.2 \%$ and $0.12 \%$ digluconate chlorhexidine mouth rinses on the level of dental staining and gingival indices. Dent. Res. J. (Isfahan), 9, 305-308.

Ogura, H., Kato, Y., and Shinoda, H. (1999) Modern Dental Pharmacology (in Japanese). pp.592, Ishiyaku shuppan, 
Tokyo.

Satomura, K., Kitamura, T., Kawamura, T., Shimbo, T., Watanabe, M., Kamei, M., Takano, Y., and Tamakoshi, A. (2005) Prevention of upper respiratory tract infections by gargling: a randomized trial. Am. J. Prev. Med., 29, 302-307.

Shibuya, M. (1988) Studies on Available lodine (I2) of PVP-I Solution and its Reaction with Saliva (in Japanese). J Dent HIth., 38, 172-179.

Shim, J.Y., Yim, S.B., Chung, J.H., and Hong, K.S. (2012) Antiplaque and antigingivitis effects of a mouthrinse containing cetylpyridinium chloride, triclosan and dipotassium glycyrrhizinate. J Periodontal Implant Sci. , 42, 33-38.

Soutome, S., Yanamoto, S., Funahara, M., Hasegawa, T., Komori, T., Yamada, S.I., Kurita, H., Yamauchi, C., Shibuya, Y., Kojima, Y., Nakahara, H., Oho, T., and Umeda, M. (2017) Effect of perioperative oral care on prevention of postoperative pneumonia associated with esophageal cancer surgery: A multicenter case-control study with propensity score matching analysis. Medicine (Baltimore), 96, e7436.

Sreenivasan, P.K., Haraszthy, V.I., and Zambon, J.J. (2013)
Antimicrobial efficacy of $0.05 \%$ cetylpyridinium chloride mouthrinses. Lett Appl Microbiol., 56, 14-20.

Sugita, N., Nakasone, N., Hanai, Y., Takahashi, M., Ito, H., Morozumi, T., Kubota, T., Okuda, K., and Yoshie, H. (2014) Microbiological effects of a low-concentration Chlorhexidine Hydrochloride/ cetylpyridinium chloride mouth rinse for patients with periodontitis (in Japanese). Jpn J Conserv Dent. , 57, 219-228.

Takagi, A., Saito, H., Kurimura, T., Kanemasa, Y., and Utsumi, S. (1989) Essentials of Microbiology, Third Edition (in Japanese). pp.132, Ishiyaku shuppan, Tokyo.

Uzer Celik E., Tunac A.T., Ates M and Sen B.H. Antimicrobial activity of different disinfectants against cariogenic microorganisms. (2016) Braz. Oral Res., 30, e125.

van der Mei, H.C., Perdok, J.F., Genet, M., Rouxhet, P.G., and Busscher, H.J. (1990) Cetylpyridinium chloride adsorption on the wettability and elemental surface composition of human enamel. Clin. Prev. Dent., 12, 25-29.

Yoneyama, T., Yoshida, M., Matsui, T., and Sasaki, H. (1999) Oral care and pneumonia. Oral Care Working Group. Lancet, 354, 515. 